\title{
Structural Characterisation of ZnO Particles Obtained by the Emulsion Precipitation Method
}

\author{
Agnieszka Kołodziejczak-Radzimska, ${ }^{1}$ Ewa Markiewicz, ${ }^{2}$ and Teofil Jesionowski ${ }^{1}$ \\ ${ }^{1}$ Institute of Chemical Technology and Engineering, Faculty of Chemical Technology, Poznan University of Technology, \\ M. Sklodowskiej-Curie 2, 60965 Poznan, Poland \\ ${ }^{2}$ Institute of Molecular Physics, Polish Academy of Science, M. Smoluchowskiego 17, 60179 Poznan, Poland
}

Correspondence should be addressed to Teofil Jesionowski, teofil.jesionowski@put.poznan.pl

Received 25 May 2012; Accepted 20 September 2012

Academic Editor: Huogen Yu

Copyright ( 2012 Agnieszka Kołodziejczak-Radzimska et al. This is an open access article distributed under the Creative Commons Attribution License, which permits unrestricted use, distribution, and reproduction in any medium, provided the original work is properly cited.

Zinc oxide was obtained by precipitation in an emulsion system with zinc acetate used as a precursor of $\mathrm{ZnO}$ and potassium hydroxide or sodium hydroxide as a precipitating agent. The cyclohexane, as an organic phase, and a nonionic surfactant mixture were also used for preparation of the emulsion. By applying modifications of the $\mathrm{ZnO}$ precipitation process, such as changing the precipitating agent, composition of substrates, and the rate of substrate dosing, some interesting structures of $\mathrm{ZnO}$ particles were obtained. The morphology of the modified samples was analysed based on SEM (scanning electron microscope) and TEM (transmission electron microscope) images. Moreover the samples were characterised by determination of their dispersive properties using the noninvasive back scattering method (NIBS), adsorption parameters (BET), and crystalline structure (XRD). Thermogravimetric analysis (TG) as well as infrared spectrophotometry (FT-IR) was also applied. For selected samples their electrical properties (dielectric permittivity and electric conductivity) were also measured. The zinc oxide obtained consisted of particles in the shapes of solids, ellipsoids, rods, and flakes, with size ranging from 164 to $2670 \mathrm{~nm}$ and showed well-developed surface area with values as high as $20 \mathrm{~m}^{2} / \mathrm{g}$.

\section{Introduction}

Zinc oxide, with its unique physical and chemical properties such as high chemical stability, high electrochemical coupling coefficient, broad range of radiation absorption, and high photostability, is a multifunctional material [1-3]. In material science zinc oxide is classified as a semiconductor in groups II-VI, whose covalence is at the border between ionic and covalent semiconductors. A broad energy band $(3.37 \mathrm{eV})$, high bond energy $(60 \mathrm{meV})$, and high thermal and mechanical stability at room temperature make it attractive for potential use in electronics, optoelectronics, and laser technology [4-7]. The piezo- and pyroelectric properties of $\mathrm{ZnO}$ mean that it can be used as a sensor, converter, energy generator, and photocatalyst in hydrogen production. Compared with $\mathrm{TiO}_{2}, \mathrm{ZnO}$ as a potential photocatalyst has the advantage of lower cost, absorption of more light quanta, and higher photocatalytic efficiencies for the degradation of several organic pollutants in both acidic and basic media compared with $\mathrm{TiO}_{2}$ [8]. Many strategies have been developed to improve the photocatalytic activity of $\mathrm{ZnO}$ nanostructures, such as changing the structural and morphological characteristics (size, shape, and crystalline structure) [9]. Because of ZnO's hardness, rigidity, and piezoelectric constant it is a material important in the ceramics industry, while its low toxicity, biocompatibility, and biodegradability make it a material of interest for biomedicine and in proecological systems [10]. Zinc oxide occurs in a very rich variety of structures and offers a wide range of properties [11, 12]. A variety of methods for $\mathrm{ZnO}$ production $[13,14]$, such as a vapour deposition process [15], precipitation in water solution [16], hydrothermal synthesis $[17,18]$, a sol-gel process [19], precipitation from microemulsions [20], and a mechanochemical process [21], make it possible to obtain products with particles differing in shape, size, and spatial structure. 
Zinc oxide can occur in one-(1D), two-(2D), and threedimensional (3D) structures. One-dimensional structures make up the largest group, including nanorods [22, 23], -needles [24], -helixes, -springs and -rings [25], -ribbons [26], -tubes [27-29], -belts [30], -wires [31], -combs [32], and so forth; 1D structures were synthesised by Shouli et al. [33]. The same authors obtained three different morphological forms of zinc oxide, namely needles, pencils, and flowers, in the process of hydrothermal precipitation in the presence of CTAB and SDS. Their results pointed to the important role of surfactants in the morphology of the zinc oxide nanocrystals. When studying the relation between the gas properties and calcination conditions, the same authors established that the best crystallisation of zinc oxide and highest effectiveness of gas reactions were obtained for $\mathrm{ZnO}$ synthesis at $400^{\circ} \mathrm{C}$ for 1 hour.

Zinc oxide can be obtained in 2D structures, for example, nanoplate/nanosheet and nanopellets $[34,35]$. Such particles have been obtained by Leung et al. [36], who precipitated $\mathrm{ZnO}$ with a structure of ribbons/combs by heating a mixture of $\mathrm{ZnO}$ : SWNT (single-walled carbon nanotubes) in a pipe furnace under atmospheric pressure. The morphology of the samples so obtained depends on the calcination temperature and substrates used. $\mathrm{ZnO}$ in the form of ribbons/combs shows strong UV absorption, which testifies to high purity of the crystalline samples obtained.

Examples of 3D structures of zinc oxide include flower, dandelion, snowflakes, coniferous urchin-like, and so forth $[4,37-40]$. ZnO with a 3D structure has been obtained by Haldar et al. [41], who applied the method of chemical condensation of vapours using zinc acetate as a precursor. They obtained zinc oxide in the form of nanorods joined in a kind of flower-like structure. The 3D structures are composed of $\mathrm{ZnO}$ nanorods of about $50 \mathrm{~nm}$ in diameter, hierarchically arranged about a common nucleus.

In this paper we report on the obtaining of $\mathrm{ZnO}$ in different morphological forms, by the method of emulsion precipitation (an alternative to the classical precipitation method and other frequently used complex procedures), with zinc acetate as a precursor of $\mathrm{ZnO}$ and potassium or sodium hydroxide as a precipitating agent.

\section{Experimental Procedure}

2.1. Materials. The precursors of zinc oxide were $0.9 \mathrm{M}$, $1.4 \mathrm{M}$, and $1.9 \mathrm{M}$ solutions of dihydrate zinc acetate $\mathrm{Zn}\left(\mathrm{CH}_{3} \mathrm{COO}\right)_{2} \cdot \mathrm{H}_{2} \mathrm{O}$ (Chempur). The precipitating agent was a $1.8 \mathrm{M}$ solution of potassium hydroxide $\mathrm{KOH}$ or sodium hydroxide $\mathrm{NaOH}$, both from Chempur. Also used in emulsion formation were cyclohexane (Chempur) as an organic phase, and nonylphenylpolyoxyethylene glycol ethers NP3 and NP6 (Sigma-Aldrich) as a mixture of emulsifiers. All reagents were of analytical grade.

2.2. Emulsion Precipitation. Appropriate quantities of the emulsifiers (NP3 and NP6) were weighed and dissolved in the organic phase (cyclohexane), to which zinc acetate was added in a proper concentration. The mixture was homogenised for 30 minutes, after which the emulsion was ready for $\mathrm{ZnO}$ precipitation. Precipitation was carried out in a reactor of $500 \mathrm{~cm}^{3}$ capacity equipped with a homogenizer. The emulsion was placed in the reactor, to which a solution of $\mathrm{KOH}$ (or $\mathrm{NaOH}$ ) was dosed using an Ismatec ISM833A type peristaltic pump. The system was intensely stirred $(9000 \mathrm{rpm})$. The system obtained as a result of the reaction taking place in the reactor (QVF Mini-Plant Pilot Tec) was subjected to destabilisation at $80^{\circ} \mathrm{C}$. Then the organic phase was separated by the vacuum evaporation technique and the mixture obtained was filtered off under reduced pressure. Next the sample was washed with hot water and methanol to remove residues of the emulsifiers. The filtrate cake was then dried in a stationary drier at $120^{\circ} \mathrm{C}$ to obtain the final product $\mathrm{ZnO}$. Four samples were obtained, labelled as Z1, Z2, Z3, and Z4, composed of particles of different shapes. Table 1 presents the conditions of precipitation and main data for the samples, and Figure 1 shows the scheme for obtaining $\mathrm{ZnO}$ from the emulsion systems.

\subsection{Physicochemical Characteristics of Precipitated $\mathrm{ZnO}$}

2.3.1. Dispersive Properties. Particle size distributions were determined using a Zetasizer Nano ZS (Malvern Instruments Ltd.), an analyser based on the noninvasive back scattering method (NIBS). Cumulant analysis gives a width parameter known as the polydispersity, or the polydispersity index (PdI). Cumulant analysis is actually the fit of a polynomial to the log of the G1 correlation function (1):

$$
\operatorname{Ln}[\mathrm{G} 1]=a+b t+c t^{2}+d t^{3}+e t^{4}+\cdots .
$$

The value of $b$ is known as the second order cumulant, or the $z$-average diffusion coefficient. The coefficient of the squared term, $c$, when scaled as $2 c / b^{2}$, is known as the polydispersity.

2.3.2. Scanning Electron Microscopy. At the next stage, morphology and microstructure were investigated to obtain data on dispersion, grain morphology, structure of individual particles, and agglomeration types in the obtained zinc oxide. The studies were performed using a Zeiss EVO40 scanning electron microscope and a Jeol 1200 EX II transmission electron microscope.

2.3.3. Adsorption Properties. In order to characterise the adsorption properties, nitrogen adsorption/desorption isotherms at $77 \mathrm{~K}$ and parameters such as surface area $\left(A_{\mathrm{BET}}\right)$, total volume $\left(V_{p}\right)$, and mean size $\left(\mathrm{S}_{p}\right)$ of pores were determined using an ASAP 2020 instrument (Micromeritics Instrument Co.). All samples were degassed at $120^{\circ} \mathrm{C}$ for $4 \mathrm{~h}$ prior to measurement. The surface area was determined by the multipoint BET (Brunauer-Emmett-Teller) method using the adsorption data as a function of relative pressure $\left(p / p_{0}\right)$. The BJH (Barrette-Joyner-Halenda) method was applied to determine the pore volume and the average pore size.

2.3.4. X-Ray Diffraction. The crystalline structure of individual samples was resolved using the $\mathrm{X}$-ray diffraction 


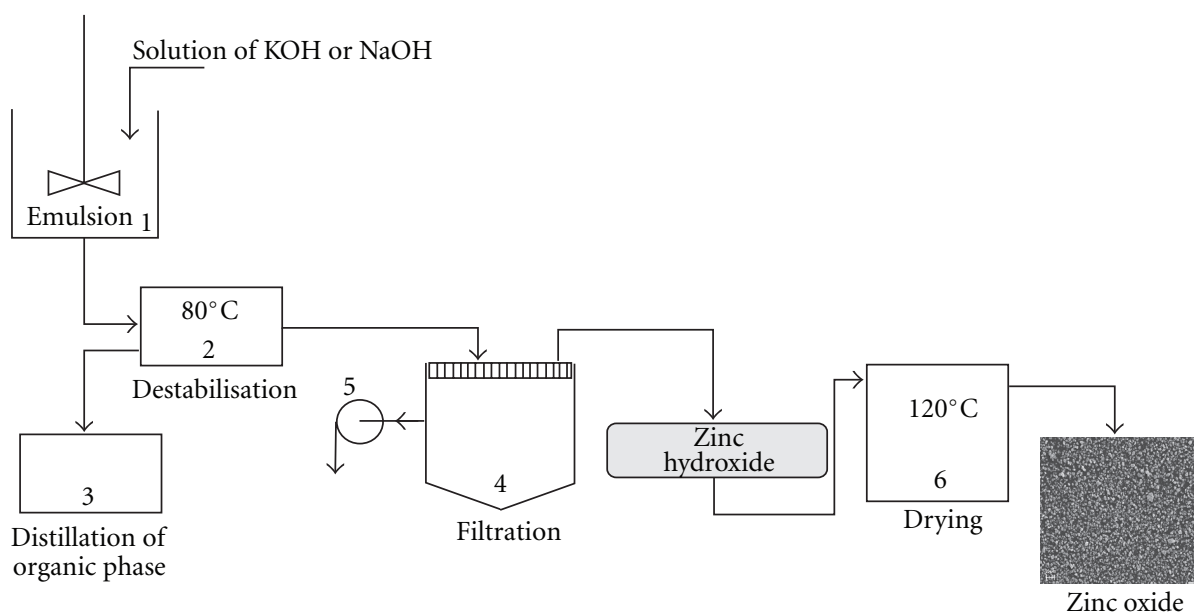
(1) Reactor
(4) Pressure filter
(2) Water bath
(5) Vacuum pump
(3) Vacuum evaporator
(6) Dryer

FIgURE 1: Scheme for emulsion precipitation of zinc oxide.

TABLE 1: Experimental conditions of the precipitation process and particle shapes determined for the zinc oxides obtained.

\begin{tabular}{|c|c|c|c|c|c|}
\hline Sample code & $\begin{array}{c}\text { Concentration of } \\
\mathrm{Zn}\left(\mathrm{CH}_{3} \mathrm{COO}\right)_{2} \text { solution }(\mathrm{M})\end{array}$ & Precipitating agent & $\begin{array}{c}\text { Amount of zinc } \\
\text { acetate/cyclohexane } \\
\left(\mathrm{cm}^{3}\right) \\
\end{array}$ & $\begin{array}{c}\text { Dosing rate of } \mathrm{KOH} \text { (or } \\
\mathrm{NaOH}) \text { to } \\
\mathrm{Zn}\left(\mathrm{CH}_{3} \mathrm{COO}\right)_{2}\left(\mathrm{~cm}^{3} / \mathrm{min}\right)\end{array}$ & Particle shape \\
\hline $\mathrm{Z1}$ & 0.9 & $\mathrm{KOH}$ & $50 / 50$ & 11 & Solids \\
\hline $\mathrm{Z} 2$ & 0.9 & $\mathrm{KOH}$ & $150 / 180$ & 11 & Ellipsoids \\
\hline $\mathrm{Z3}$ & 1.4 & $\mathrm{KOH}$ & $150 / 180$ & 4 & Rods \\
\hline $\mathrm{Z} 4$ & 1.9 & $\mathrm{NaOH}$ & $50 / 60$ & 4 & Flakes \\
\hline
\end{tabular}

method. The diffractograms were recorded using a TURM-62 horizontal diffractometer, equipped with HZG-3 type goniometer. To obtain the radiation intensity distribution curve $I=f(\theta)$, a counting rate gauge was used, interoperating with the counter and electronically coupled to a graphic recorder.

2.3.5. Thermal Stability. A thermogravimetric analyser (TG, model Jupiter STA 449F3, made by Netzsch) was used to investigate the thermal decomposition behaviour of the samples. Measurements were carried out under flowing nitrogen at a heating rate of $10^{\circ} \mathrm{C} / \mathrm{min}$ and a temperature range of 25$1000^{\circ} \mathrm{C}$ with an initial sample weight of approximately $5 \mathrm{mg}$.

2.3.6. Fourier Transform Infrared Spectroscopy (FT-IR). In order to identify the characteristic groups present on the surface of the precipitated $\mathrm{ZnO}$, the samples were subjected to FT-IR analysis using an IFS $66 \mathrm{v} / \mathrm{s}$ spectrophotometer (Bruker). The samples were studied in the form of $\mathrm{KBr}$ tablets, as $\mathrm{KBr}$ crystals are inactive in the IR range. The analysis was performed over a range of $4000-400 \mathrm{~cm}^{-1}$.

2.3.7. Dielectric Properties and Conductivity. Dielectric properties of the samples were characterised by determination of the dielectric constant, conductivity, and refractive index. Dielectric and conductivity measurements were performed at room temperature in the range $10^{-2}-10^{7} \mathrm{~Hz}$ on an impedance analyser (Alpha-A High Performance Frequency Analyzer, Novocontrol $\mathrm{GmbH}$ ). The refractive index was determined by approximation of the curves representing the frequency dependence of permittivity.

\section{Results and Discussion}

3.1. Dispersive and Morphological Characterisation of Zinc Oxide. SEM and TEM images of the $\mathrm{ZnO}$ samples precipitated from the emulsion system when different process parameters were applied (Table 1) revealed different and interesting structures of the products. Solid (sample Z1), ellipsoid (Z2), rod (Z3), and flake (Z4) morphologies were observed.

Figure 3 presents the particle size distributions recorded for the four samples. The low values of the polydispersity index $(\mathrm{Z} 1-\mathrm{PdI}=0.161, \mathrm{Z2}-\mathrm{PdI}=0.168, \mathrm{Z} 3-$ $\mathrm{PdI}=0.127$, and $\mathrm{Z} 4-\mathrm{PdI}=0.055)$ imply that the particles have relatively high homogeneity and direct regular shapes (confirmed in the SEM and TEM images, see Figure 2). The particle size distributions display monomodal bands covering narrow ranges of particle diameters. The smallest 


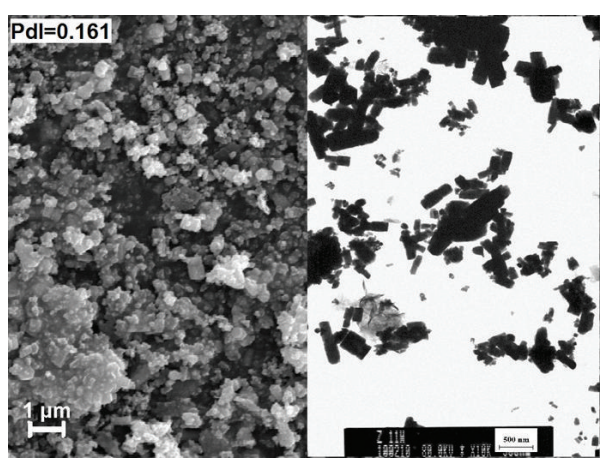

(a)

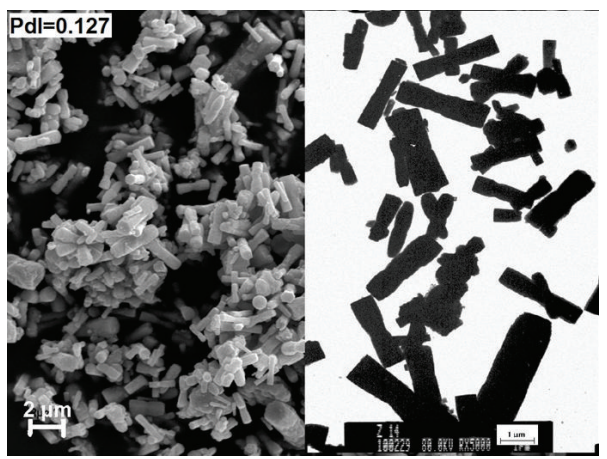

(c)

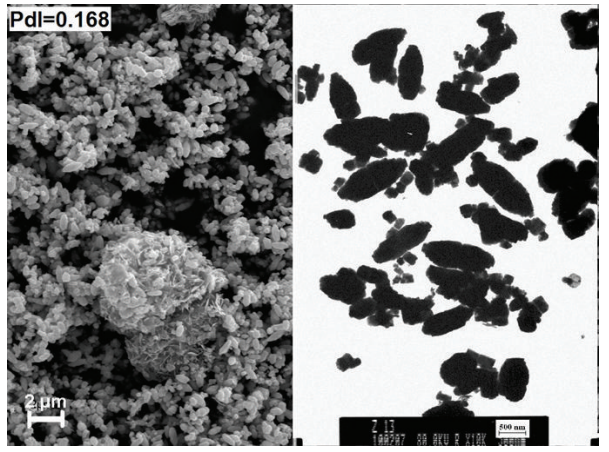

(b)

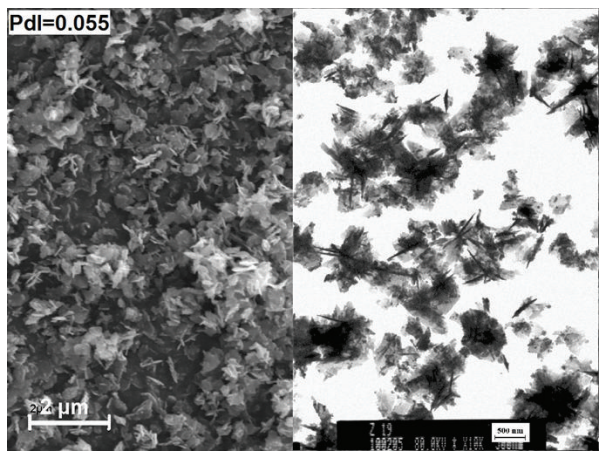

(d)

Figure 2: SEM and TEM images of zinc oxide structures: (a) sample Z1, (b) Z2, (c) Z3, and (d) Z4.

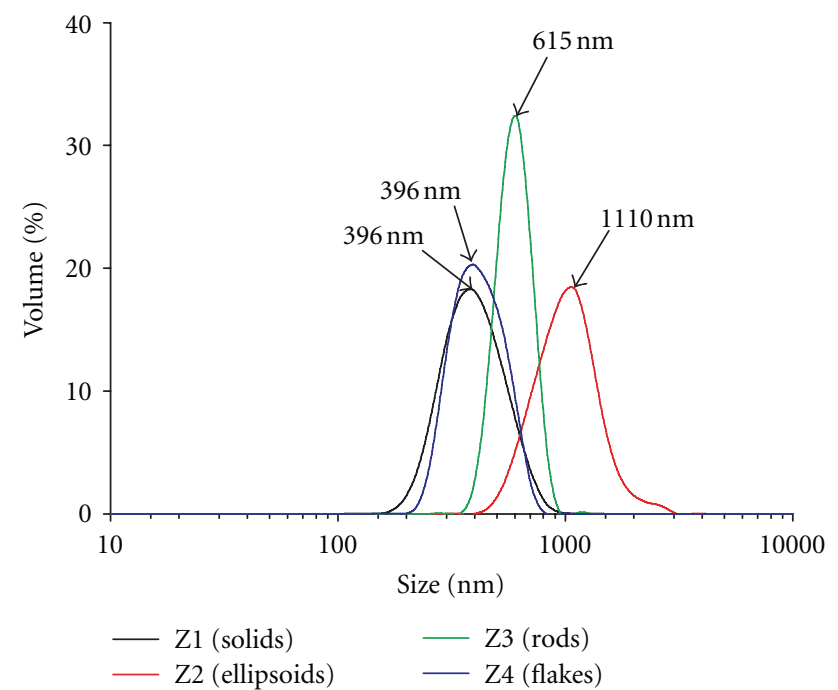

Figure 3: Particle size distributions of precipitated $\mathrm{ZnO}$ powders.

size particles were obtained in sample Z1 (solids) and Z4 (flakes); their diameters varied in the range $164-955 \mathrm{~nm}$ (sample Z1) and 220-712 nm (sample Z4). The maximum volume contribution (close to 20\%) came from particles of $396 \mathrm{~nm}$ diameter. The ellipsoid structures present in sample $\mathrm{Z} 4$ had diameters in the range $459-2670 \mathrm{~nm}$; the maximum volume contribution of about $30 \%$ came from particles of $1110 \mathrm{~nm}$ diameter. The rod structures observed in sample Z3 had diameters in the range $396-825 \mathrm{~nm}$, and the maximum volume contribution of about $20 \%$ came from particles of $815 \mathrm{~nm}$ diameter. By changing the precipitating agent ( $\mathrm{KOH}$ or $\mathrm{NaOH}$ ) we can vary the resulting $\mathrm{ZnO}$ particle structures. Using $\mathrm{KOH}$ results in two-dimensional shapes (solids, ellipsoids, rods). However when $\mathrm{NaOH}$ is used, we obtain particles in the form of flakes. The morphology is also affected by the concentration of zinc acetate and the quantity of the organic phase. It was observed in particular that as the quantity of the organic phase increases, there is an increase in the parameter reflecting the length of the resulting particles (a powder in the form of nanorods is obtained).

3.2. Adsorption Properties. Nitrogen adsorption/desorption isotherms and pore size distributions of the $\mathrm{ZnO}$ samples obtained are shown in Figure 4. The isotherms were classified as type IV and the hysteresis loops as type H3, which points to the mesoporous structure of the $\mathrm{ZnO}$ samples. A type IV isotherm is related to capillary condensation taking place in mesopores. As can be seen in Figure 4, the $\mathrm{ZnO}$ samples obtained in the manner described above have large specific surface areas, the largest $\left(23 \mathrm{~m}^{2} / \mathrm{g}\right)$ being recorded for sample Z4 (flakes, Figure 4(d)). The pore volume and mean pore diameter in this sample were $0.015 \mathrm{~cm}^{3} / \mathrm{g}$ and $2.6 \mathrm{~nm}$, respectively. The smallest specific surface area $\left(8 \mathrm{~m}^{2} / \mathrm{g}\right)$ was determined for sample Z1 (solids, Figure 4(a)), and the pore volume and mean pore diameter in this sample were $0.006 \mathrm{~cm}^{3} / \mathrm{g}$ and $2.9 \mathrm{~nm}$. The specific surface areas of sample Z2 (ellipsoids, Figure 4(b)) and sample Z3 (rods, Figure 4(c)) 


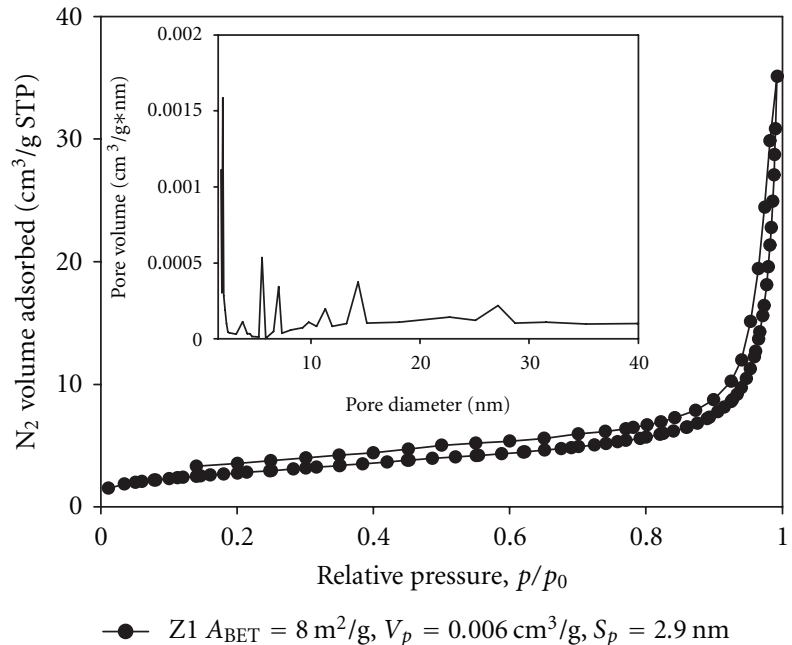

(a)

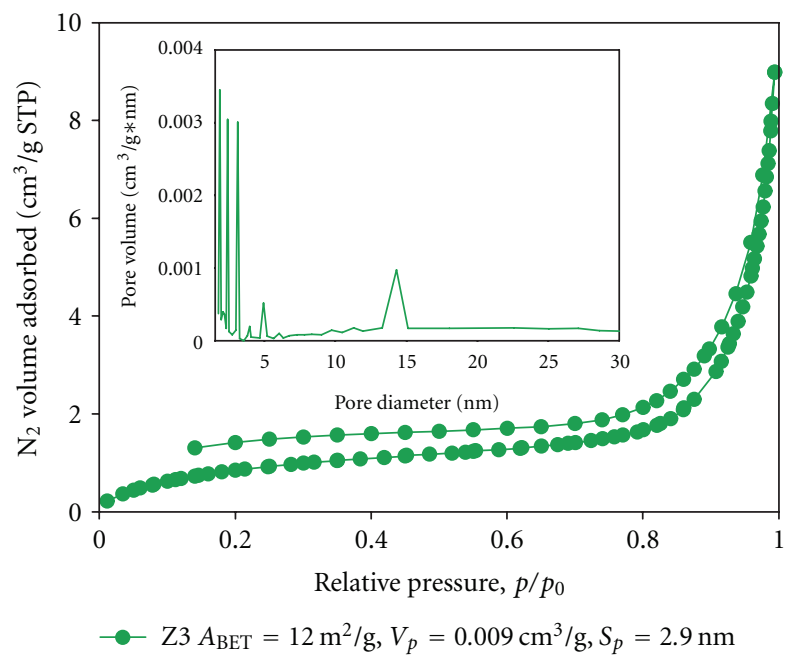

(c)

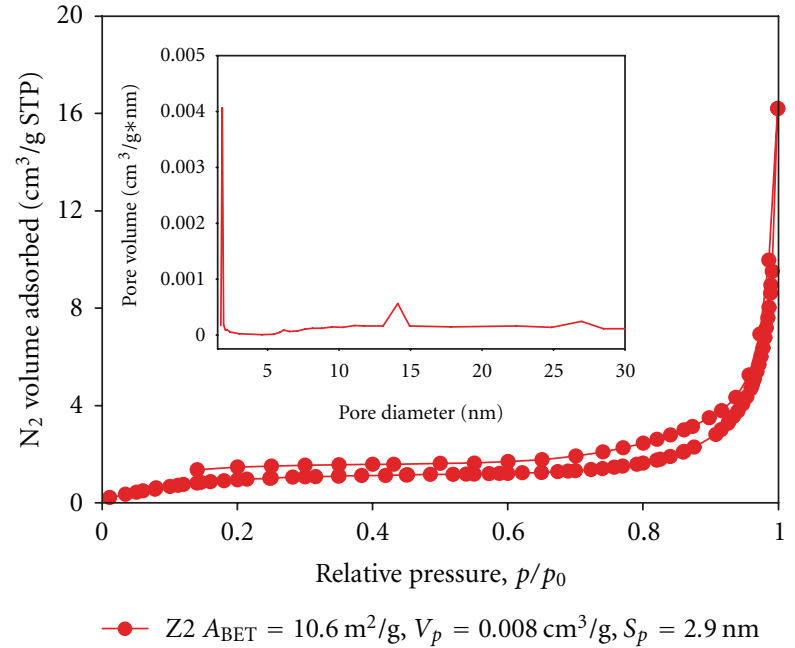

(b)

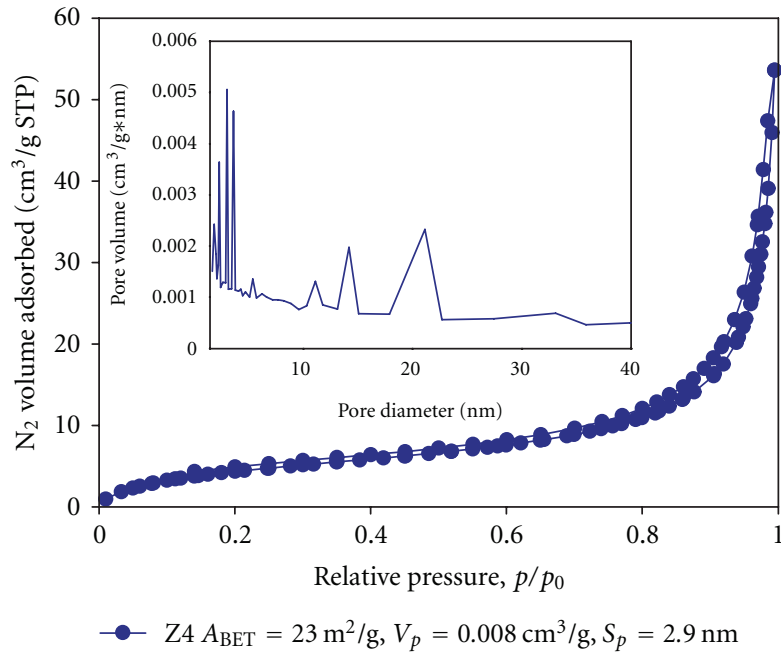

(d)

Figure 4: Nitrogen adsorption/desorption isotherms and pore size distributions of ZnO samples (a) Z1, (b) Z2, (c) Z3, and (d) Z4.

were 10.8 and $12.0 \mathrm{~m}^{2} / \mathrm{g}$, while their pore volumes were 0.008 and $0.009 \mathrm{~cm}^{3} / \mathrm{g}$ and the mean pore diameters 2.7 and $2.9 \mathrm{~nm}$, respectively. From analysis of the parameters of the $\mathrm{ZnO}$ precipitation process it can be concluded that with an increase in the concentration of zinc acetate and the quantity of the organic phase (cyclohexane) there is an increase in the specific surface area of the resulting samples. In addition the type of precipitating agent used significantly influences on the adsorption activity.

3.3. X-Ray Diffraction. The crystalline structure of the obtained zinc oxide samples was resolved by the X-ray diffraction method (XRD). WAXS diffraction patterns (Figure 5) confirmed the crystalline structure of the samples. All diffraction maxima observed correspond to the hexagonal structure of $\mathrm{ZnO}$ (JCPDS card number 36-1451 [4]). The diffraction maxima observed at the $2 \theta$ angles $31.8,34.5,36.3$, 47.6, and 56.6 correspond to the characteristic $\mathrm{ZnO}$ planes of wurtzite structure: (100); (002); (101); (102); (110) [27, 28].
The average crystal size ( $D_{\text {average }}$ ) of the $\mathrm{ZnO}$ samples was estimated from the width of lines in the XRD spectrum using the Sherrer equation:

$$
D=\frac{K \lambda}{\beta \cos \theta}
$$

where $K$ is a unitless constant taken as $0.9, \lambda$ is the $\mathrm{X}$-ray wavelength (1.5418 $\AA$ ), $\beta$ is the width of the line at halfmaximum intensity, and $\theta$ is half of the diffraction angle [42]. The $D_{\text {average values were calculated for the three highest }}$ intense peaks of the $\mathrm{ZnO}$ spectrum, which are (101), (002), and (100). The calculated average crystal sizes are detailed in Table 2.

3.4. Thermal Stability. The $\mathrm{ZnO}$ samples obtained were subjected to thermogravimetric (TG) analysis, which provides information on the chemical and physical transformations taking place upon heating. The TG curves recorded are 


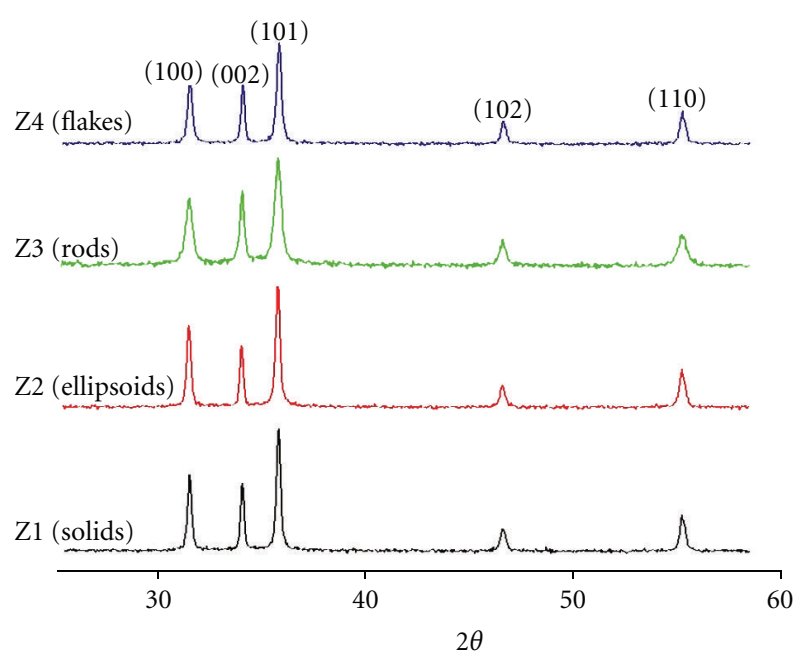

FIGURE 5: XRD diffraction patterns of zinc oxide structures.

TABLE 2: Calculated average crystal size of $\mathrm{ZnO}$ using the Scherrer equation.

\begin{tabular}{lcccc}
\hline $\begin{array}{l}\text { Sample } \\
\text { code }\end{array}$ & $D_{(101)}(\mathrm{nm})$ & $D_{(002)}(\mathrm{nm})$ & $D_{(100)}(\mathrm{nm})$ & $D_{\text {average }}(\mathrm{nm})$ \\
\hline Z1 & 38.1 & 76.9 & 46.2 & 53.7 \\
Z2 & 57.0 & 76.9 & 57.7 & 63.8 \\
Z3 & 45.9 & 76.9 & 76.8 & 66.5 \\
Z4 & 32.7 & 76.9 & 57.7 & 41.3 \\
\hline
\end{tabular}

presented in Figure 6. The greatest mass loss, of about $20 \%$ was observed for samples Z1 (solids) and Z3 (rods). For Z1 this decrease occurred in the temperatures range $20-500^{\circ} \mathrm{C}$, while for $\mathrm{Z} 3$ it occurred in the two ranges $20-400^{\circ} \mathrm{C}$ and 400 $800^{\circ} \mathrm{C}$. A smaller mass loss of about $15 \%$ taking place in the range $20-500^{\circ} \mathrm{C}$ was noted for samples $\mathrm{Z} 2$ (ellipsoids) and Z4 (flakes). The mass loss in all samples is related to desorption of physically adsorbed water molecules on the $\mathrm{ZnO}$ surface. It follows that the degradation of samples $Z 1$ and $Z 3$ is faster than that of Z2 and Z4. The mass loss is caused mainly by thermal decomposition combined with water loss (water of crystallisation and constitutional water).

3.5. Spectroscopic Studies. In order to identify the characteristic groups present on the surface of the $\mathrm{ZnO}$ samples that could react with the functional groups of other compounds, the zinc oxides were subjected to spectroscopic analysis. The FT-IR spectra taken for samples Z2 (ellipsoids) and Z4 (flakes) are presented in Figure 7.

The spectroscopic analysis confirmed previously published results [43-45]. The spectra reveal the presence of bands assigned to the oscillating vibrations $\nu \mathrm{O}-\mathrm{H}$ $\left(\sim 3400 \mathrm{~cm}^{-1}\right)$, symmetric and asymmetric valency bands $\nu \mathrm{C}-\mathrm{H}\left(\sim 3000 ; 1050 \mathrm{~cm}^{-1}\right)$ and stretching vibrations $\nu \mathrm{C}=\mathrm{O}$ $\left(\sim 1300 ; 1500 \mathrm{~cm}^{-1}\right), v \mathrm{Zn}-\mathrm{OH}\left(\sim 900 \mathrm{~cm}^{-1}\right)$, and $v \mathrm{Zn}-\mathrm{O}$ $\left(\sim 450 \mathrm{~cm}^{-1}\right)$. The spectroscopic studies indirectly provide information about the surface character of the $\mathrm{ZnO}$ samples

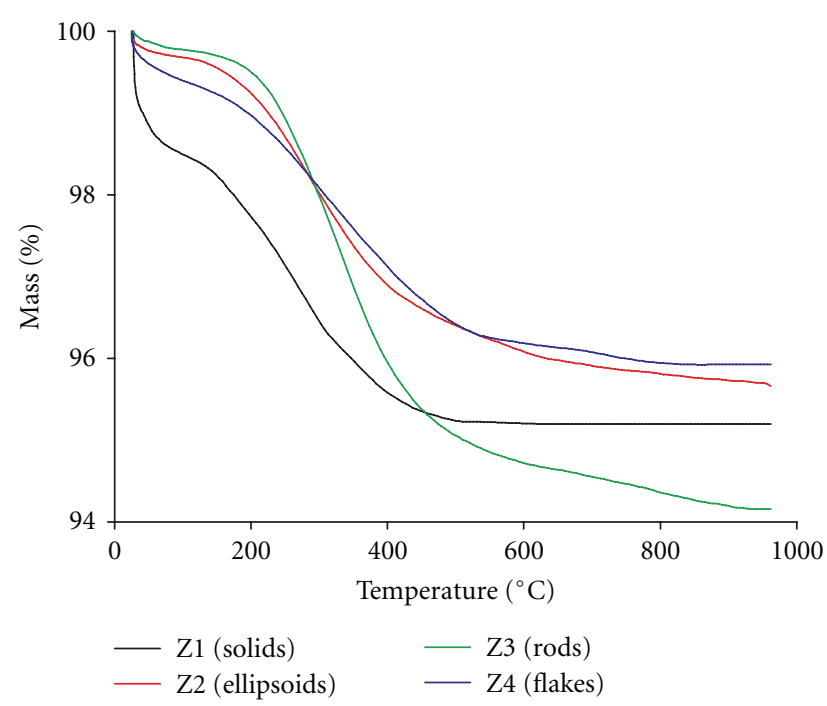

FIGURE 6: Thermal analysis curves for the obtained samples of zinc oxide.

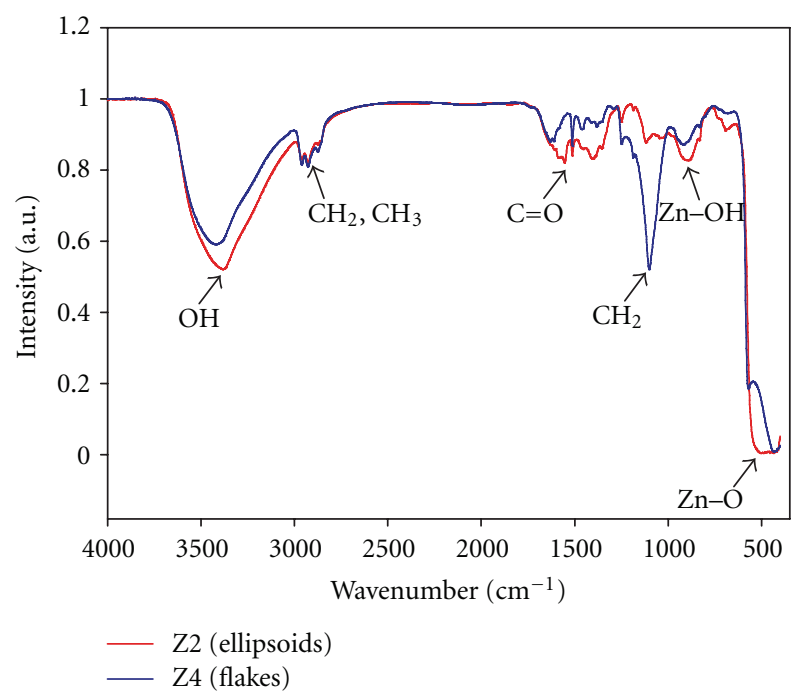

FIGURE 7: FT-IR spectra of precipitated zinc oxide: Z2 (ellipsoids) and Z4 (flakes).

(intensity of hydroxyl group bands), which is of importance in applications of zinc oxide in nonpolar systems.

3.6. Electrical Properties. Figure 8 presents the relation of frequency versus permittivity $\mathcal{\varepsilon}^{\prime}$ measured for samples $\mathrm{Z} 2$ (ellipsoids) and Z4 (flakes). These two materials show high dispersion (strong dependence of permittivity versus frequency). The significant increase in permittivity in the low frequency range (below $100 \mathrm{~Hz}$ ) is related to the large influence of conductivity. For frequencies above $10 \mathrm{kHz}$ a tendency towards stabilisation of permittivity is observed, which is typical for dielectric materials at frequencies higher than the range corresponding to reorientational and ionic polarisation. 


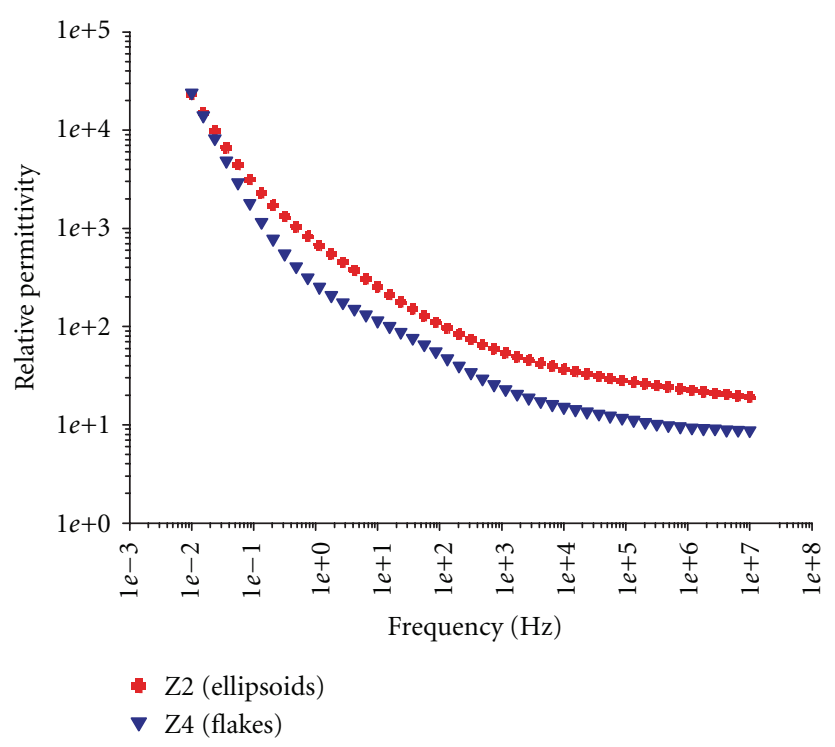

FIGURE 8: Permittivity $\varepsilon^{\prime}$ versus frequency for zinc oxide samples Z2 and $\mathrm{Z} 4$.

Figure 9 presents the conductivity $\sigma^{\prime}$ of samples Z2 and $\mathrm{Z} 4$ as a function of frequency.

The values of conductivity measured for samples Z2 and $\mathrm{Z} 4$ are typical for insulators. In the frequency range 1$10000 \mathrm{kHz}$, the conductivity is described by relation (3):

$$
\sigma_{a c}^{\prime}(\omega) \propto \omega^{P}
$$

In the entire frequency $(\omega)$ range studied, the exponent $P$ is 0.75 for $\mathrm{Z} 4$ (flakes) and 0.97 for $\mathrm{Z} 2$ (ellipsoids). For sample Z2 the character of the frequency dependence of conductivity is more gradual, while for Z4 it is more diffusional. The nature of the graph of conductivity versus frequency depends on the concentration of zinc acetate and the precipitating agent used. A smaller concentration of $\mathrm{Zn}\left(\mathrm{CH}_{3} \mathrm{COO}\right)_{2}(0.9 \mathrm{M})$ and use of $\mathrm{KOH}$ make the curve more gradual, while increasing the concentration $(1.4 \mathrm{M})$ and introducing $\mathrm{NaOH}$ produce a more diffusional curve. In the lowest frequency range the dependence shows a plateau characteristic of ohmic conductivity. The refractive index at the optical frequencies satisfies the following relation:

$$
n \approx \sqrt{\varepsilon} .
$$

For the samples studied this index was determined by approximation of the curves of frequency against permittivity. The values obtained are given in Table 3 . The refractive index is influenced significantly by the reaction parametersan increase in the concentration of zinc acetate and the use of $\mathrm{NaOH}$ instead of $\mathrm{KOH}$ as the precipitating agent cause a decrease in the value of this parameter.

\section{Conclusions}

Zinc oxide has been obtained in a number of different structures using a large number of methods which has so

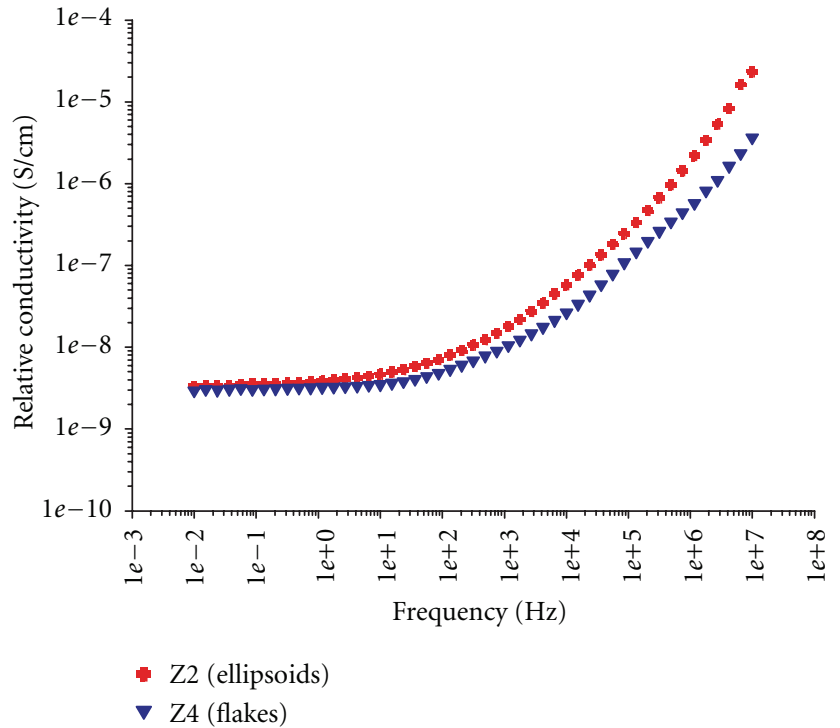

Figure 9: The dependence of conductivity $\sigma^{\prime}$ versus frequency for samples Z2 and Z4.

TABLE 3: Refractive index of precipitated samples Z2 and Z4.

\begin{tabular}{lc}
\hline Sample symbol & Refractive index $n$ \\
\hline Z2 & 2.42 \\
Z4 & 1.95
\end{tabular}

far been proposed. The relatively simple method for $\mathrm{ZnO}$ synthesis proposed in this paper makes it possible to obtain $\mathrm{ZnO}$ with particles in the shape of solids, ellipsoids, rods and flakes, and with very well-developed surface area. The structures of the product particles were found to depend on certain types of modification to the precipitation process. The analysis shows that the results obtained are clearly influenced by the parameters of the precipitation process. The shape of the $\mathrm{ZnO}$ particles depends on the concentration of zinc acetate, the type of precipitating agent, and the quantity of the organic phase. The diameters of the $\mathrm{ZnO}$ particles obtained varied in the range $164-2670 \mathrm{~nm}$, while the specific surface areas ranged from 8 to $24 \mathrm{~m}^{2} / \mathrm{g}$. The samples were found to display the crystalline structure of hexagonal wurtzite. The high value of the refractive index (close to 2.2), and high chemical resistance are very important and attractive features for potential applications. In summary, the proposed method of precipitation makes it possible to obtain $\mathrm{ZnO}$ powders with various interesting structures and properties, desirable for many applications. The same method can be used for obtaining oxides of other metals characterised by different nano- and microstructures. In the next stage of this research the zinc oxide obtained will be used as a photocatalyst.

\section{Conflict of Interests}

The authors informed equal contribution of each author in this paper and declared any conflict of interests in respect of our submitted paper. 


\section{Acknowledgments}

This work was supported by Poznan University of Technology Research Grant no. 32-329/2012 DS-MK. The authors would like to thank Dominik Paukszta for his assistance with the XRD analysis.

\section{References}

[1] D. Segets, J. Gradl, R. K. Taylor, V. Vassilev, and W. Peukert, "Analysis of optical absorbance spectra for the determination of $\mathrm{ZnO}$ nanoparticle size distribution, solubility, and surface energy," ACS Nano, vol. 3, no. 7, pp. 1703-1710, 2009.

[2] T. Parvin, N. Keerthiraj, I. A. Ibrahim, S. Phanichphant, and K. Byrappa, "Photocatlytic degradation of municipal wastewater and brilliant blue dye using hydrothermally synthesized surface-modified silver-doped $\mathrm{ZnO}$ designer particles," International Journal of Photoenergy, vol. 2012, Article ID 670610, 8 pages, 2012.

[3] Ü. Özgür, Y. I. Alivov, C. Liu et al., "A comprehensive review of $\mathrm{ZnO}$ materials and devices," Journal of Applied Physics, vol. 98, no. 4, Article ID 041301, pp. 1-103, 2005.

[4] J. Wang, J. Cao, B. Fang, P. Lu, S. Deng, and H. Wang, "Synthesis and characterization of multipod, flower-like, and shuttle-like $\mathrm{ZnO}$ frameworks in ionic liquids," Materials Letters, vol. 59, no. 11, pp. 1405-1408, 2005.

[5] E. Bacaksiz, M. Parlak, M. Tomakin, A. Özçelik, M. Karakiz, and M. Altunbaş, "The effects of zinc nitrate, zinc acetate and zinc chloride precursors on investigation of structural and optical properties of $\mathrm{ZnO}$ thin films," Journal of Alloys and Compounds, vol. 466, no. 1-2, pp. 447-450, 2008.

[6] K. K. Devarepally, D. C. Cox, A. T. Fry, V. Stolojan, R. J. Curry, and M. Munz, "Synthesis of linear $\mathrm{ZnO}$ structures by a thermal decomposition method and their characterization," Journal of Material Science, vol. 47, no. 4, pp. 1893-1901, 2012.

[7] P. H. Huh and S.-C. Kim, "Nanostructured $\mathrm{ZnO}$ arrays with self- $\mathrm{ZnO}$ layer created using simple electrostatic layer-by-layer assembly," Journal of Nanonmaterials, vol. 2012, Article ID 131672, 6 pages, 2012.

[8] L. Y. Yang, S. Y. Dong, J. H. Sun, J. L. Feng, Q. H. Wu, and S. P. Sun, "Microwave-assisted preparation, characterization and photocatalytic properties of a dumbbell-shaped $\mathrm{ZnO}$ photocatalyst," Journal of Hazardous Materials, vol. 179, no. 13, pp. 438-443, 2010.

[9] Y. Zhang, W. Zhang, and H. Zheng, "Fabrication and photoluminescence properties of $\mathrm{ZnO}: \mathrm{Zn}$ hollow microspheres," Scripta Materialia, vol. 57, no. 4, pp. 313-316, 2007.

[10] H. Cao, J. Y. Xu, D. Z. Zhang et al., "Spatial confinement of laser light in active random media," Physical Review Letters, vol. 84, no. 24, pp. 5584-5587, 2000.

[11] J. Liu, X. Huang, Y. Li, K. M. Sulieman, F. Sun, and X. He, "Selective growth and properties of zinc oxide nanostructures," Scripta Materialia, vol. 55, no. 9, pp. 795-798, 2006.

[12] Z. L. Wang, "Splendid one-dimensional nanostructures of zinc oxide: a new nanomaterial family for nanotechnology," ACS Nano, vol. 2, no. 10, pp. 1987-1992, 2008.

[13] R. Hong, T. Pan, J. Qian, and H. Li, "Synthesis and surface modification of $\mathrm{ZnO}$ nanoparticles," Chemical Engineering Journal, vol. 119, no. 2-3, pp. 71-81, 2006.

[14] M. L. Kahn, M. Monge, V. Collière, F. Senocq, A. Maisonnat, and B. Chaudret, "Size- and shape-control of crystalline zinc oxide nanoparticles: a new organometallic synthetic method,"
Advanced Functional Materials, vol. 15, no. 3, pp. 458-468, 2005.

[15] E. Galoppini, J. Rochford, H. Chen et al., "Fast electron transport in metal organic vapor deposition grown dye-sensitized ZnO nanorod solar cells," Journal of Physical Chemistry B, vol. 110, no. 33, pp. 16139-16161, 2006.

[16] H. Sun, M. Luo, W. Weng et al., "Room-temperature preparation of $\mathrm{ZnO}$ nanosheets grown on $\mathrm{Si}$ substrates by a seedlayer assisted solution route," Nanotechnology, vol. 19, no. 12, Article ID 125603, 2008.

[17] A. A. Ismail, A. El-Midany, E. A. Abdel-Aal, and H. El-Shall, "Application of statistical design to optimize the preparation of $\mathrm{ZnO}$ nanoparticles via hydrothermal technique," Materials Letters, vol. 59, no. 14-15, pp. 1924-1928, 2005.

[18] Y. Hou, M. Yang, G. Pang, and S. Feng, "ZnO microrods with etched surface prepared by two-step hydrothermal reaction," Journal of Materials Science, vol. 43, no. 7, pp. 2149-2152, 2008.

[19] M. Ristić, S. Musić, M. Ivanda, and S. Popović, "Solgel synthesis and characterization of nanocrystalline $\mathrm{ZnO}$ powders," Journal of Alloys and Compounds, vol. 397, no. 1-2, pp. L1-L14, 2005.

[20] X. Li, G. He, G. Xiao, H. Liu, and M. Wang, "Synthesis and morphology control of $\mathrm{ZnO}$ nanostructures in microemulsions," Journal of Colloid and Interface Science, vol. 333, no. 2, pp. 465-473, 2009.

[21] A. Moballegh, H. R. Shahverdi, R. Aghababazadeh, and A. R. Mirhabibi, "ZnO nanoparticles obtained by mechanochemical technique and the optical properties," Surface Science, vol. 601, no. 13, pp. 2850-2854, 2007.

[22] D. Banerjee, J. Y. Lao, D. Z. Wang et al., "Large-quantity freestanding ZnO nanowires," Applied Physics Letters, vol. 83, no. 10, pp. 2061-2063, 2003.

[23] Y. Li, W. F. Li, G. Xu, X. L. Ma, and H. M. Cheng, "ZnO microcolumns originated from self-assembled nanorods," Journal of Materials Science, vol. 43, no. 5, pp. 1711-1715, 2008.

[24] R. Wahab, S. G. Ansari, Y. S. Kim, H. K. Seo, and H. S. Shin, "Room temperature synthesis of needle-shaped $\mathrm{ZnO}$ nanorods via sonochemical method," Applied Surface Science, vol. 253, no. 18, pp. 7622-7626, 2007.

[25] X. Y. Kong, Y. Ding, R. Yang, and Z. L. Wang, "Single-crystal nanorings formed by epitaxial self-coiling of polar nanobelts," Science, vol. 303, no. 5662, pp. 1348-1351, 2004.

[26] Z. W. Pan, Z. R. Dai, and Z. L. Wang, "Nanobelts of semiconducting oxides," Science, vol. 291, no. 5510, pp. 19471949, 2001.

[27] M. Yang, G. Pang, L. Jiang, and S. Feng, "Hydrothermal synthesis of one-dimensional zinc oxides with different precursors," Nanotechnology, vol. 17, no. 1, pp. 206-212, 2006.

[28] P. B. Khoza, M. J. Moloto, and L. M. Sikhwivhilu, "The effect of solvents, acetone, water and ethanol, on the morphological and optical properties of $\mathrm{ZnO}$ nanoparticles prepared by microwave," Journal of Nanotechnology, vol. 2012, Article ID 195106, 6 pages, 2012.

[29] W. J. Chen, W. L. Liu, S. H. Hsieh, and T. K. Tsai, "Preparation of nanosized $\mathrm{ZnO}$ using $\alpha$ brass," Applied Surface Science, vol. 253, no. 16, pp. 6749-6753, 2007.

[30] Y. Huang, J. He, Y. Zhang et al., "Morphology, structures and properties of $\mathrm{ZnO}$ nanobelts fabricated by $\mathrm{Zn}$-powder evaporation without catalyst at lower temperature," Journal of Materials Science, vol. 41, no. 10, pp. 3057-3062, 2006. 
[31] L. C. Tien, S. J. Pearton, D. P. Norton, and F. Ren, "Synthesis and microstructure of vertically aligned $\mathrm{ZnO}$ nanowires grown by high-pressure-assisted pulsed-laser deposition," Journal of Materials Science, vol. 43, no. 21, pp. 6925-6932, 2008.

[32] T. Xu, P. Ji, M. He, and J. Li, "Growth and structure of pure ZnO micro/nanocombs," Journal of Nanomaterials, vol. 2012, Article ID 797935, 5 pages, 2012.

[33] B. Shouli, C. Liangyuan, L. Dianqing et al., "Different morphologies of $\mathrm{ZnO}$ nanorods and their sensing property," Sensors and Actuators, B, vol. 146, no. 1, pp. 129-137, 2010.

[34] W. S. Chiu, P. S. Khiew, M. Cloke et al., "Photocatalytic study of two-dimensional $\mathrm{ZnO}$ nanopellets in the decomposition of methylene blue," Chemical Engineering Journal, vol. 158, no. 2, pp. 345-352, 2010.

[35] M. José-Yacamán, C. Gutierrez-Wing, M. Miki, D. Q. Yang, K. N. Piyakis, and E. Sacher, "Surface diffusion and coalescence of mobile metal nanoparticles," Journal of Physical Chemistry $B$, vol. 109, no. 19, pp. 9703-9711, 2005.

[36] Y. H. Leung, A. B. Djurišić, J. Gao et al., "Zinc oxide ribbon and comb structures: synthesis and optical properties," Chemical Physics Letters, vol. 394, no. 4-6, pp. 452-457, 2004.

[37] R. Wahab, Y. S. Kim, and H. S. Shin, "Synthesis, characterization and effect of $\mathrm{pH}$ variation on zinc oxide nanostructures," Materials Transactions, vol. 50, no. 8, pp. 2092-2097, 2009.

[38] J. Liu, X. Huang, Y. Li, J. Duan, and H. Ai, "Large-scale synthesis of flower-like $\mathrm{ZnO}$ structures by a surfactantfree and low-temperature process," Materials Chemistry and Physics, vol. 98, no. 2-3, pp. 523-527, 2006.

[39] S. L. Wang, H. W. Zhu, W. H. Tang, and P. G. Li, "Propellershaped $\mathrm{ZnO}$ nanostructures obtained by chemical vapor deposition: photoluminescence and photocatalytic properties," Journal of Nanomaterials, vol. 2012, Article ID 594290, 5 pages, 2012.

[40] Y. Chen, X. Zang, J. Gu et al., "ZnO single butterfly wing scales: synthesis and spatial optical anisotropy," Journal of Materials Chemistry, vol. 21, no. 17, pp. 6140-6143, 2011.

[41] S. R. Haldar, A. Nayak, T. K. Chini, S. K. Ray, N. Yamamoto, and S. Bhunia, "Vapor condensation growth and evolution mechanism of $\mathrm{ZnO}$ nanorod flower structures," Physica Status Solidi A, vol. 207, no. 2, pp. 364-369, 2010.

[42] N. Kilinç, L. Arda, S. Öztürk, and Z. Z. Öztürk, "Structure and electrical properties of Mg-doped $\mathrm{ZnO}$ nanoparticles," Crystal Research and Technology, vol. 45, no. 5, pp. 529-538, 2010.

[43] S. Bhattacharyya and A. Gedanken, "A template-free, sonochemical route to porous $\mathrm{ZnO}$ nano-disks," Microporous and Mesoporous Materials, vol. 110, no. 2-3, pp. 553-559, 2008.

[44] E. Tang, G. Cheng, and X. Ma, "Preparation of nano$\mathrm{ZnO} / \mathrm{PMMA}$ composite particles via grafting of the copolymer onto the surface of zinc oxide nanoparticles," Powder Technology, vol. 161, no. 3, pp. 209-214, 2006.

[45] Q. Zhu, J. Chen, Q. Zhu et al., "Monodispersed hollow microsphere of $\mathrm{ZnO}$ mesoporous nanopieces: preparation, growth mechanism and photocatalytic performance," Materials Research Bulletin, vol. 45, no. 12, pp. 2024-2030, 2010. 

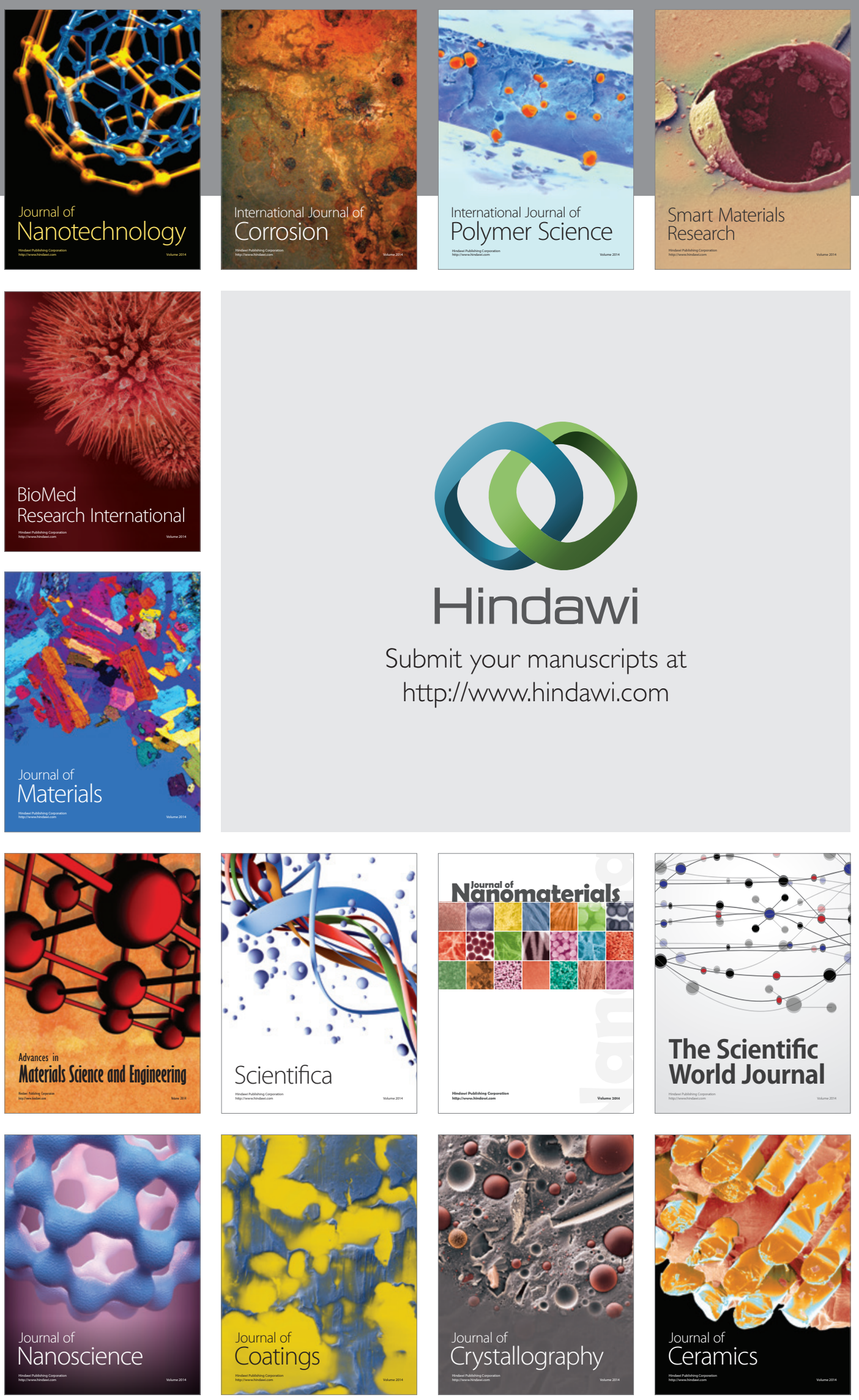

The Scientific World Journal

Submit your manuscripts at

http://www.hindawi.com

\section{World Journal}

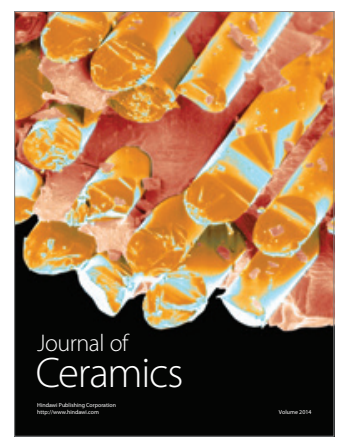

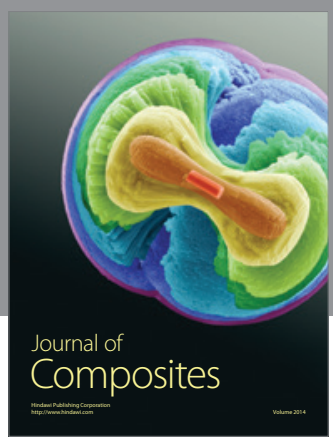
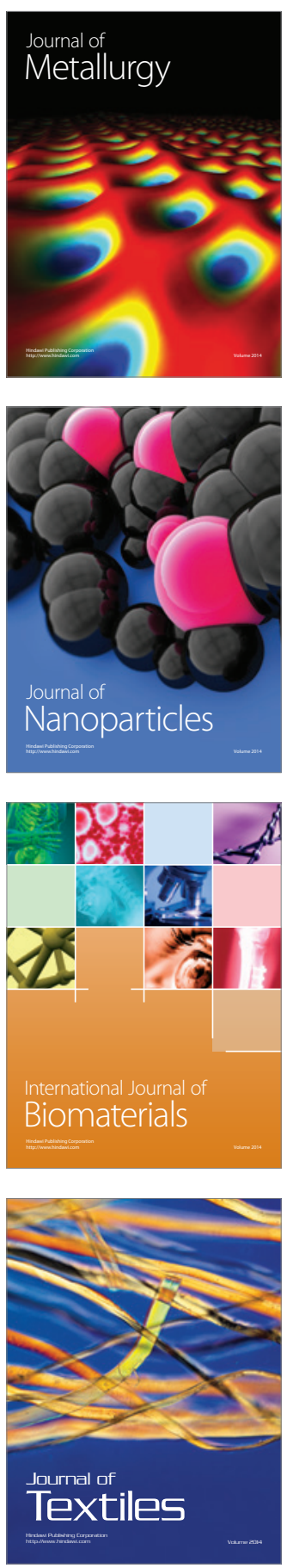